\title{
Letter to the editor: Prognostic significance of preoperative and follow-up neutrophil-to-lymphocyte ratio and platelet-to-lymphocyte ratio in patients with non-metastatic clear cell renal cell carcinoma
}

\author{
Beuy Joob ${ }^{1}$, Viroj Wiwaniitkit ${ }^{2}$ \\ ${ }^{1}$ Sanitation 1 Medical Academic Center, Bangkok, Thailand, ${ }^{2} \mathrm{dr}$ DY Patil University, Pune, India
}

This is an Open Access article distributed under the terms of the Creative Commons Attribution Non-Commercial License (http://creativecommons.org/licenses/by-nc/4.0) which permits unrestricted non-commercial use, distribution, and reproduction in any medium, provided the original work is properly cited.

To the editor:

Dear editor, we read the publication on "Prognostic significance of preoperative and follow-up neutrophil-tolymphocyte ratio (NLR) and platelet-to-lymphocyte ratio (PLR) in patients with non-metastatic clear cell renal cell carcinoma (NMCCRCC)" with a great interest [1]. In this work, preoperative NLR (pNLR) and PLR (pPLR) and relationship with recurrence-free survival (RFS) are studied. Kim et al. [1] concluded that " $p N L R$ and $p P L R$ are independent prognostic factors for RFS in patients with NMCCRCC." There are some considerations on the use of pNLR and pPLR. Both pNLR and pPLR might be affected by several confounding factors and this might be pitfall of the present study. This problem is the basic forgotten problem for clinical use of NLR and PLR as prognostic factors in several medical disorders $[2,3]$. Focusing on basic laboratory medicine principle, the neutrophil, lymphocyte and platelet investigation needs good quality control and the parameters from different analyzers might be variable [4]. The results of differential white blood counts of the same patient's sample from different analyzers are usually different [4]. For example, the result of neutrophil count performed by some analyzers comparing to manual referencing count might be lower [5].

\section{CONFLICTS OF INTEREST}

The authors have nothing to disclose.

\section{REFERENCES}

1. Kim TW, Lee JH, Shim KH, Choo SH, Choi JB, Ahn HS, et al. Prognostic significance of preoperative and follow-up neutrophil-to-lymphocyte ratio and platelet-to-lymphocyte ratio in patients with non-metastatic clear cell renal cell carcinoma. Investig Clin Urol 2019;60:14-20.

2. Wiwanitkit V. Neutrophil-to-lymphocyte ratio, platelet-to-lymphocyte ratio and heart failure. Arq Bras Cardiol 2016;106:265.

3. Wiwanitkit V. Neutrophil to lymphocyte ratio in allergic rhinitis. Eur Arch Otorhinolaryngol 2016;273:3443.

4. Bruegel M, Nagel D, Funk M, Fuhrmann P, Zander J, Teupser D. Comparison of five automated hematology analyzers in a university hospital setting: Abbott Cell-Dyn Sapphire, Beckman Coulter DxH 800, Siemens Advia 2120i, Sysmex XE-5000, and Sysmex XN-2000. Clin Chem Lab Med 2015;53:1057-71.

5. Park Y, Song J, Song S, Song KS, Ahn MS, Yang MS, et al. Evaluation of the Abbott Cell-Dyn Sapphire hematology analyzer. Korean J Lab Med 2007;27:162-8.

Received: 12 February, 2019 • Accepted: 8 March, 2019 Corresponding Author: Beuy Joob

Sanitation 1 Medical Academic Center, Bangkok, Thailand E-mail: beuyjoob@hotmail.com 


\section{The author's reply:}

We thank the authors of the letter to the Editor for their important comments. We agree that the results of differential white blood counts may vary from analyzer to analyzer. This is perhaps one of the reasons why investigators present different cutoff neutrophil-to-lymphocyte ratio (NLR) and platelet-to-lymphocyte ratio (PLR) values that separate patients with better prognosis and worse prognosis. So, making a one-size-fits-all cutoff is useless. However, this variability does not eliminate the importance of differential counts used every day in practice. It is up to clinicians to interpret and apply these values after adjusting for their specific working environment. The same is true for NLR and PLR values in patients with renal cell carcinoma.

\section{CONFLICTS OF INTEREST}

The author has nothing to disclose.

Sun Il Kim Department of Urology, Ajou University Hospital, Ajou University School of Medicine, Suwon, Korea

Received: 7 May, 2019 • Accepted: 7 May, 2019

Corresponding Author: Sun II Kim

Department of Urology, Ajou University Hospital, Ajou University School of Medicine, 164 WorldCup-ro, Yeongtong-gu, Suwon 16499, Korea

TEL: +82-31-219-5270, FAX: +82-31-219-4803,

E-mail: sikimuro@gmail.com

ORCID: https://orcid.org/0000-0003-2674-983X

https://doi.org/10.4111/icu.2019.60.4.332 